\title{
Photochemical Efficiency and Recovery of Photosystem II in Grapes After Exposure to Sudden and Gradual Heat Stress
}

\author{
Sorkel Kadir ${ }^{1}$ and Michael Von Weihe \\ Department of Horticulture, Forestry, and Recreation Resources, Kansas State University, \\ 3734 Throckmorton Plant Science Center, Manhattan, KS 66505
}

\author{
Kassim Al-Khatib \\ Agronomy Department, Kansas State University, Manhattan, KS 66505
}

\begin{abstract}
AdDitional INDEX words. PSII, Vitis aestivalis, French-American hybrid, thermostability, thylakoids, 'Vignoles'
Abstract. Damage and capacity to recover of photosystem II (PSII) from long exposures to heat stress were investigated in grapes using chlorophyll fluorescence. Two wine grapes, Vitis aestivalis Michx. cv. 'Cynthiana' and French-American hybrid 'Vignoles' (Vitis L. hybrid), were exposed to a sudden heat shock (SHS) and a gradual heat shock (GHS) at $40 / 35{ }^{\circ} \mathrm{C}$. After heat stress, plants were moved to a greenhouse to allow PSII to recover from heat treatments. Changes in maximum quantum efficiency of PSII, indicated by the ratio of variable fluorescence and maximum fluorescence (Fv/Fm), were observed after 3, 6, and 12 days of heat stress and after 3, 7, 14, and 21 days recovery periods of damage to PSII. Total leaf area (LA) and leaf, shoot, and root biomass were determined at the end of the experiment. Regardless of the heat treatment, increasing duration of exposure to high temperature caused a decline in $\mathrm{Fv} / \mathrm{Fm}$ in both cultivars. Heat stress treatments also caused a progressive decline in $\mathrm{LA}$ as well as leaf and shoot biomass. Maximum quantum efficiency of PSII was observed after 3 days of exposure in both cultivars, regardless of the heat stress treatment. 'Vignoles', however, showed higher PSII photochemical efficiency 12 days after heat exposure. GHS was less detrimental to PSII compared with SHS heat treatment. The damaged PSII of 'Vignoles' recovered faster than that of 'Cynthiana'. A positive relationship was observed between Fv/Fm and LA of plants exposed to heat treatments. Based on Fv/Fm values, this study indicates that PSII of 'Vignoles' is more thermostable and can recover faster than that of 'Cynthiana' leaves, regardless of the heat treatment. These results suggest that 'Vignoles' is generally more heat-tolerant than 'Cynthiana' and changes in $\mathrm{Fv} / \mathrm{Fm}$ ratio under heat stress conditions could be a good indicator for screening heat-resistant grape cultivars.
\end{abstract}

The photosystem II reaction center is the most sensitive reaction center in photosynthesis to heat stress (Wen et al., 2005). Heat stress decreases photosynthetic electron transport activity and variable fluorescence and maximum fluorescence (Fv/Fm) of photosystem II (PSII). Inactivation of PSII by heat stress is related to three effects: injury to the water-splitting complex, which may recover slowly after stress; disturbance of distribution of pigment complexes in thylakoid membranes, which influences regulation of energy transfer; and blockage of the photochemical reaction center of PSII, which is irreversible, caused by the detachment of the center from the antenna (Costa et al., 2002; Wise et al., 2004). Growth of plants exposed to heat stress is slow, and recovery is gradual or impossible because injury to different parts of PSII may be stationary or permanent, depending on the temperature, duration of exposure, and acclimation (Sinsawat et al., 2004; Weis and Berry, 1988).

Chlorophyll fluorescence is used to assess changes in photosynthesis indirectly (Costa et al., 2002; Kim and Portis, 2005; Schreiber and Bilger, 1987). On the application of saturating light, fluorescence raises from the ground state value

Received for publication 21 Mar. 2007. Accepted for publication 12 July 2007. Funding for this study was provided by the College of Agriculture Honors Student Program, Kansas State University, Manhattan, Kansas. Contribution no. 07-191-J from the Kansas State Agricultural Experiment Station, Manhattan, KS

Mention of trade or company names does not imply endorsement of the products or equipment named nor criticism of similar products not named.

${ }^{1}$ Corresponding author. E-mail: skadir@ksu.edu.
(Fo) to Fm value. In the process, the first electron acceptor of PSII (QA) is fully reduced. This allows the determination of maximum quantum efficiency of PSII primary photochemistry given by the ratio of $\mathrm{Fv}$ and $\mathrm{Fm}$. Changes in the fluorescence yield reflect changes in photochemical efficiency and heat dissipation; low $\mathrm{Fv} / \mathrm{Fm}$ values in plants under stress indicate damage to the PSII reaction center.

Chlorophyll fluorescence is used to determine the effects of environmental stresses on photosynthesis in plants exposed to adverse conditions. Several field, controlled environment, and laboratory methods are available for evaluating high temperature injury and resistance (Paulsen, 1994). Chlorophyll fluorescence is one of several methods measured by instruments that detect rapid transients near the photosystems and slow transients from stromal activities (Moffatt et al., 1990). A pulse-modulated chlorophyll fluorescence meter was used in this study.

The effects of heat stress on water splitting, the efficiency of PSII reaction centers, and the light harvesting complexes of several plant species have been investigated (Costa et al., 2002; Kim and Portis, 2005; Srivastava et al., 1997). In addition, the effect of heat stress on grapes has been investigated at a whole plant and on a cellular level (Kadir, 2006). Damage to PSII in grapes was closely related to decline in photosynthesis. Varietal response to heat stress of extracted thylakoids indicated the existence of thermostability differences between grape cultivars. The extracted thylakoids of 'Cynthiana' after 2 min of exposure to temperatures higher than $20^{\circ} \mathrm{C}$ showed a decrease 
in Fv/Fm (Kadir, 2006). The lowest Fv/Fm values were measured on 'Cynthiana' and indicated that electron transfer from PSII of 'Cynthiana' is less efficient than that of Vitis vinifera L. cv. 'Pinot noir'.

To our knowledge, few experiments have addressed the capacity of damaged PSII in grapes to recover after a sudden or gradual exposure to heat shock treatments, although there have been reports covering the recovery of PSII and photosynthesis in several other species (Costa et al., 2002; Kim and Portis, 2005; Méthy et al., 1997; Sepúlveda and Kliewer, 1986). We hypothesize that if the recovery plays a role in heat tolerance in grapevines, then it is possible that recovery of PSII may exist after a period of heat stress and that the grape cultivars with contrasting tolerance to high temperature may differ in the extent of damage and recovery of PSII under heat stress.

The response of PSII to heat stress in grapevines without and with preacclimation by exposure to sudden heat shock (SHS) and gradual heat shock (GHS), respectively, to high temperature can help better understand the mechanisms involved in inhibition of PSII and thus photosynthesis.

For the past few years, grape has become one of the most productive and important specialty crops in the midwestern United States with Vitis labrusca L. and the French-American hybrid cultivars being the dominant wine grapes for their cold hardiness. 'Cynthiana' is one of the most widely planted red wine cultivar as a result of rich, dark-red, spicy, raspberryscented wine. 'Cynthiana' and 'Vignoles' were selected for being the most popular grapes grown in the northeastern and midwestern regions. 'Cynthiana' growth in the field stops as temperature increases above $35^{\circ} \mathrm{C}$ (S. Jennings, personal communication) and is severely injured under controlled conditions after 4 weeks exposure to $40 / 35{ }^{\circ} \mathrm{C}$ (Kadir, 2005, 2006). Nonetheless, little information exists on the heat tolerance and mechanism by which 'Vignoles' survives high temperatures. The objectives of this study were to examine the maximum quantum efficiency of PSII, measured by Fv/Fm, of 'Cynthiana' and 'Vignoles' exposed to SHS and GHS treatments at $40 / 35{ }^{\circ} \mathrm{C}$ and to investigate the capacity of PSII to recover from heat stress conditions.

\section{Materials and Methods}

Plant materials and heat treatments. Two independent experiments were conducted under controlled environmental conditions. Dormant cuttings of 'Cynthiana' and 'Vignoles' were planted in May 2004 and Nov. 2004. The cuttings were planted in 1 sand : 1 peatmoss : 1 perlite (by volume) medium mix in polyethylene pots $(16.25 \times 16.25 \times 12.5 \mathrm{~cm})$ under greenhouse conditions. Vines were placed in a greenhouse at 22 day $/ 17$ night $\pm 3{ }^{\circ} \mathrm{C}(\mathrm{D} / \mathrm{N})$ temperatures, $50 \% \pm 10 \%$ relative humidity (RH), and 16/8-h photoperiods. Supplemental light intensity on a horizontal plane above the canopy was 200 $\mu \mathrm{mol} \cdot \mathrm{m}^{-2} \cdot \mathrm{s}^{-1}$ photosynthetic photon flux $(P P F)(400$ to $700 \mathrm{~nm}$, measured with LI-188B Integrating Quantum/Radiometer/Photometer; LI-COR, Lincoln, NE) using grow lights with 400-W, high-pressure sodium S-51 type lamps (Hydrofarm Products, Petaluma, CA). Vines were irrigated daily to full pot capacity (Olson et al., 2000) and fertilized weekly with a commercial fertilizer containing $300 \mu \mathrm{g} \cdot \mathrm{L}^{-1}$ nitrogen, $250 \mu \mathrm{g} \cdot \mathrm{L}^{-1}$ phosphorus, and $220 \mu \mathrm{g} \cdot \mathrm{L}^{-1}$ potassium (Miracle-Gro; Scotts MiracleGro Products, Port Washington, NY). After 4 months of growth under greenhouse conditions, vines were divided into several groups, each of 18 vines (nine per cultivar): control, SHS, and GHS plants. Before exposing vines to heat treatments, all vines were pruned to a single shoot and chlorophyll fluorescence of the most recent, fully expanded leaf of the SHS and GHS groups was measured. Chlorophyll fluorescence measurements of the SHS and GHS plants before applying heat treatments were considered as the control. For leaf area (LA) and dry tissue biomass, the control, SHS, and GHS plants were measured after $21 \mathrm{~d}$ of recovery.

The SHS vines were transferred to a growth chamber (CMP 3244; Conviron, Asheville, NC) set at $40 / 35 \pm 1{ }^{\circ} \mathrm{C} \mathrm{D} / \mathrm{N}$ temperatures, $16 / 8$-h photoperiods, $550 \mu \mathrm{mol} \mathrm{m}{ }^{-2} \cdot \mathrm{s}^{-1} \cdot P P F$, and RH ranged between $40 \% \pm 10 \%$ during the light period to $70 \%$ $\pm 10 \%$ during the night period. Plants were exposed to SHS treatment for 3,6 , and $12 \mathrm{~d}$, and then taken out of the growth chamber and placed under the greenhouse conditions mentioned earlier for recovery from heat stress. The GHS vines were transferred to a growth chamber with similar conditions to that of the SHS vines except temperature was set at $32 / 27 \pm 1{ }^{\circ} \mathrm{C}$ $\mathrm{D} / \mathrm{N}$. The vines were exposed to a gradual temperature increase $\left(2{ }^{\circ} \mathrm{C}\right.$ per $2 \mathrm{~d}$ ) to $40 / 35 \pm{ }^{\circ} \mathrm{C} 1 \mathrm{D} / \mathrm{N}$ for 3,6 , and $12 \mathrm{~d}$ before transferring to the same greenhouse that held the SHS vines for recovery. All pots were watered as needed to full pot capacity. Between 0900 and $1100 \mathrm{HR}$, plants were assessed for damage/ recovery to thylakoid membranes and PSII by measuring chlorophyll fluorescence after $0,3,6$, and $12 \mathrm{~d}$ of SHS and GHS exposure in the growth chambers and after 3, 7, 14, and 21 $\mathrm{d}$ of recovery periods in the greenhouse.

Assessment of DAMAGe TO THYLAKOID MEMBRANeS AND PHOTOSYSTEM II. Damage and recovery of PSII was assessed by leaf chlorophyll fluorescence emission using a pulse-modulated Fluorescence Monitoring System (FMS-1; Hansatech Instruments Ltd., Norfolk, UK) as described elsewhere (Kadir, 2006) and operated in the Fv/Fm mode. The fluorometer probe was placed $7 \mathrm{~mm}$ away from the leaf surface and measurements were made at steady state of $2000 \mu \mathrm{mol} \cdot \mathrm{m}^{-2} \cdot \mathrm{s}^{-1}$ light and saturating state of $5000 \mu \mathrm{mol} \cdot \mathrm{m}^{-2} \cdot \mathrm{s}^{-1}$ light for $0.7 \mathrm{~s}$ when all of the PSII reaction centers were reduced. Initial fluorescence when QA is fully oxidized, Fm when QA is transiently fully reduced, variable fluorescence $(\mathrm{Fv}=\mathrm{Fm}-\mathrm{Fo})$, and $\mathrm{Fv} / \mathrm{Fm}$ of PSII were recorded. Three readings from the center of the most recent, fully expanded leaf of each vine were averaged to represent one observation. The Fv/Fm value was used to assess thermostability of thylakoid membranes, and data are presented as a percentage of the control (measurements before applying heat treatments).

Plant growth measurements. After $21 \mathrm{~d}$ of recovery in the greenhouse, LA per vine of heat-treated and the control plants was measured using the LI-3100 Leaf Area Meter (LI-COR). Roots were washed on the day of harvest and allowed to dry in the greenhouse for $1 \mathrm{~d}$; roots, leaves, and shoots then were dried at $70{ }^{\circ} \mathrm{C}$ for $72 \mathrm{~h}$, weighed, and total biomass was calculated.

EXPERIMENTAL DESign AND STATISTICAL ANALysis. The experiments were randomized complete block designs with factorial arrangement of cultivar $\times$ treatment $\times$ time. The experiment was repeated and data were averaged across both runs, because there was no interaction between treatments and runs. Data were tested for homogeneity of variance and normality of distribution (Ramsey and Schafer, 1997). Temperature treatment response was determined by analyses of variance or general linear model, as appropriate. Least significant differences among means were tested at $P=0.05$ and 
precision was measured by the coefficient of variation percentage. Standard errors of treatment means were calculated.

\section{Results and Discussion}

Regardless of the heat treatment, $12 \mathrm{~d}$ of exposure to heat stress caused damage to the thylakoid membranes in both cultivars as indicated by a decrease in $\mathrm{Fv} / \mathrm{Fm}$ value and that indicated a decline in maximum quantum efficiency of PSII (Fig. 1AB). Nonetheless, cultivars differed in the extent of the damage from duration of exposure to heat treatments. The highest damage (highest decline in $\mathrm{Fv} / \mathrm{Fm}$ ratio, which equates the lowest tolerance to heat stress) was observed in 'Cynthiana'
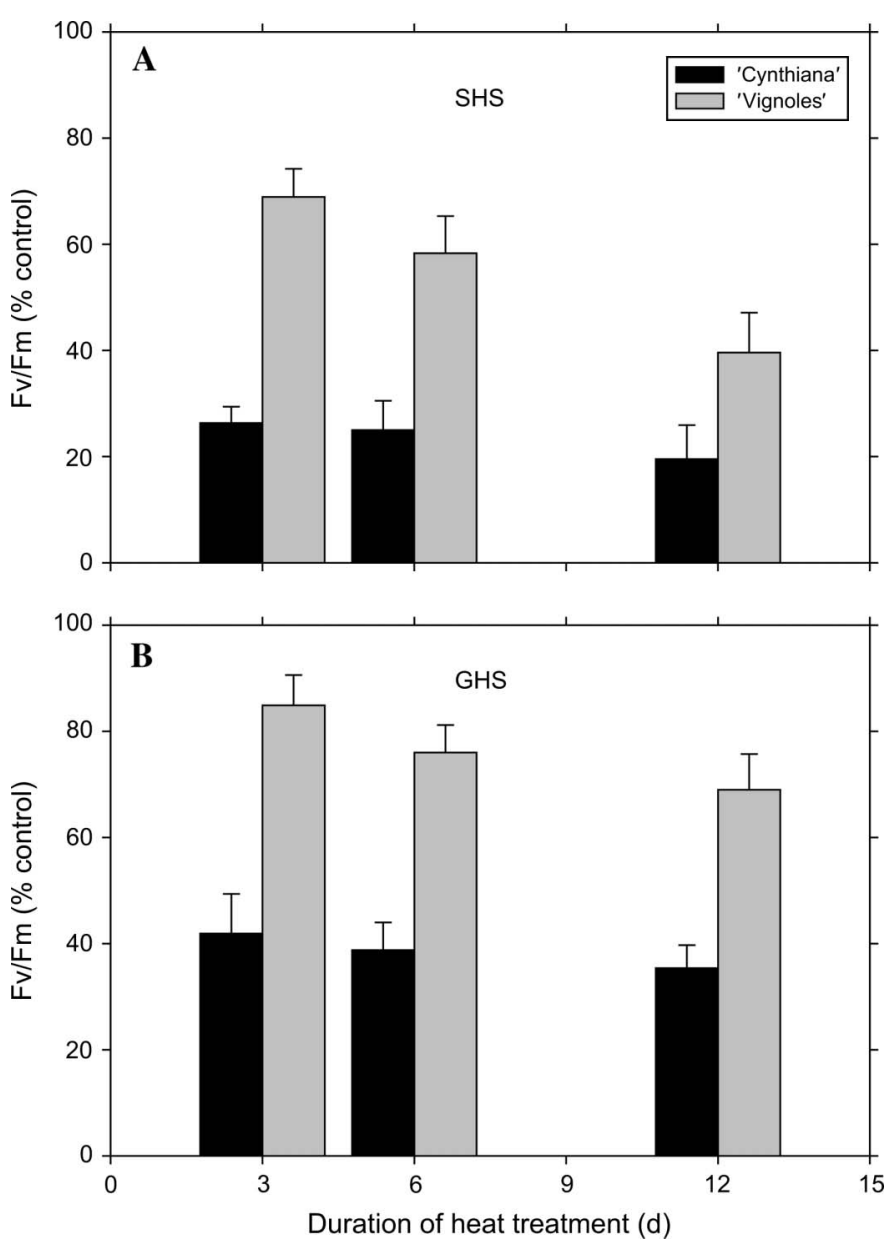

Fig. 1. The ratio of variable fluorescence and the maximum fluorescence (Fv/ Fm) of 'Cynthiana' (black bars) and 'Vignoles' (gray bars) of the most recent, fully expanded grape leaf under heat stress conditions. Four-month-old vines were exposed to sudden heat shock (SHS) (A) and gradual heat shock (GHS) (B) at 40 day $/ 35$ night ${ }^{\circ} \mathrm{C}(\mathrm{D} / \mathrm{N})$ temperatures, 16/8-h photoperiods, 550 $\mu \mathrm{mol} \cdot \mathrm{m}^{-2} \cdot \mathrm{s}^{-1} P P F$, and relative humidity ranged between $40 \% \pm 10 \%$ during the light period to $70 \% \pm 10 \%$ during the night period. Chlorophyll fluorescence was measured after 3, 6, and $12 \mathrm{~d}$ of exposure to heat treatments. The Fv/Fm ratios of heat-stressed plants are expressed as a percentage of the control (measurements before applying heat treatments). A decrease in Fv/Fm ratio indicates damage to thylakoid membranes; the lower the damage, the higher the tolerance to heat stress. A similar influence of heat treatments on Fv/Fm was observed in a duplicate experiment. Vertical lines through data points are SE. The control values for Fv/Fm at SHS and GHS measured under greenhouse conditions were 0.59 and 0.63 for 'Cynthiana' and 0.69 and 0.71 for 'Vignoles', respectively. The control treatment was measured at 22/17 \pm 3 ${ }^{\circ} \mathrm{C} \mathrm{D} / \mathrm{N}, 50 \% \pm 10 \% \mathrm{RH}$, and $16 / 8$-h photoperiods. after $12 \mathrm{~d}$ of exposure to SHS (Fig. 1A), whereas the lowest damage (lowest decline in Fv/Fm, which equates to the highest tolerance to heat stress) was observed in 'Vignoles' after $3 \mathrm{~d}$ of exposure to GHS (Fig. 1B). The Fv/Fm ratio of 'Vignoles' plants after $12 \mathrm{~d}$ of exposure to SHS (Fig. 1A) was not significantly different from that of 'Cynthiana' plants exposed for $12 \mathrm{~d}$ to GHS (Fig. 1B). Average declines in Fv/Fm under SHS treatment for 'Cynthia' and 'Vignoles' were $76 \%$ and $44 \%$, respectively, of the control (measurements before applying heat treatments). Decline in Fv/Fm of plants under GHS conditions, compared with plants under SHS conditions, was less severe for both cultivars. There was a $24 \%$ decline in 'Vignoles' compared with a 61\% decline in 'Cynthiana' leaves. Decline in PSII efficiency in both cultivars might be attributed to several factors, including damage to oxygen-evolving apparatus (Enami et al., 1994) and impairment of electron transfer within PSII reaction centers (Bukhov et al., 1999; Crafts-Brandner and Salvucci, 2002; Kourril et al., 2004) and downstream of PSII (Sinsawat et al., 2004). In addition, a decrease in $\mathrm{Fv} / \mathrm{Fm}$ during heat stress indicates a reduction of the rate of energy-trapping by PSII centers (Havaux, 1993), which might be the result of a physical dissociation of the light harvesting complex from the PSII center (Srivastava et al., 1997). Strawberry plants (Fragaria $\times$ ananassa Duchesne ex Rozier) exposed to gradual heat stress were injured less than shock heat stress treatment, and total protein and DNA contents were highest in gradual heat stress than shock heat stress plants (Gulen and Eris, 2003).

The capacity of PSII to recover from heat stress after 3, 6 , and $12 \mathrm{~d}$ of exposure to SHS and GHS heat treatments is presented in Figure 2. In general, the efficiency of PSII was recovered, although cultivars differed in the extent and ability to recover under the two heat treatments. Regardless of the duration of exposure to the SHS treatment, PSII of 'Vignoles' recovered to almost $82 \%$ of the control after $3 \mathrm{~d}$ of recovery compared with 57\% in 'Cynthiana'. Twenty-one days of recovery after SHS treatment resulted in almost total recovery of PSII (94\%) of 'Vignoles', whereas 'Cynthiana' PSII recovered to $63 \%$ of the control. PSII recovery from GHS stress was more rapid than the recovery after SHS stress (Fig. 3). After 12 d of exposure to GHS, average Fv/Fm of 'Vignoles' was $98 \%$ of the control compared with $75 \%$ for 'Cynthiana'. The longer the recovery period, the closer the Fv/Fm value was to the control in 'Vignoles' regardless of time of exposure to GHS. The maximum Fv/Fm in 'Cynthiana' (84\%) was recorded after 12 $\mathrm{d}$ of recovery from $3 \mathrm{~d}$ of exposure to GHS heat treatment. Our results indicated that GHS, rather than SHS, was less damaging to PSII and that decline in Fv/Fm was more severe under SHS rather than GHS. The thermal damage to PSII has been shown to be slowly reversible (Sinsawat et al., 2004) by acclimation to high temperatures. Short-term acclimation to high temperature improves thermal stability of PSII, thus preserving the function of photosynthetic apparatus at high temperatures (CraftsBrandner and Salvucci, 2002; Law and Crafts-Brandner, 1999). Acclimation also increases the critical temperature above which the photosynthetic apparatus is irreversibly damaged by heat stress (Costa et al., 2002; Kim and Portis, 2005; Sinsawat et al., 2004). Cultivar differences in the Fv/Fm ratio, especially for the GHS treatment, after periods of recovery from heat stress might be the result of differences in their capacity to develop thermal tolerance during $3 \mathrm{~d}$ of acclimation to high temperature. The time of acclimation for 

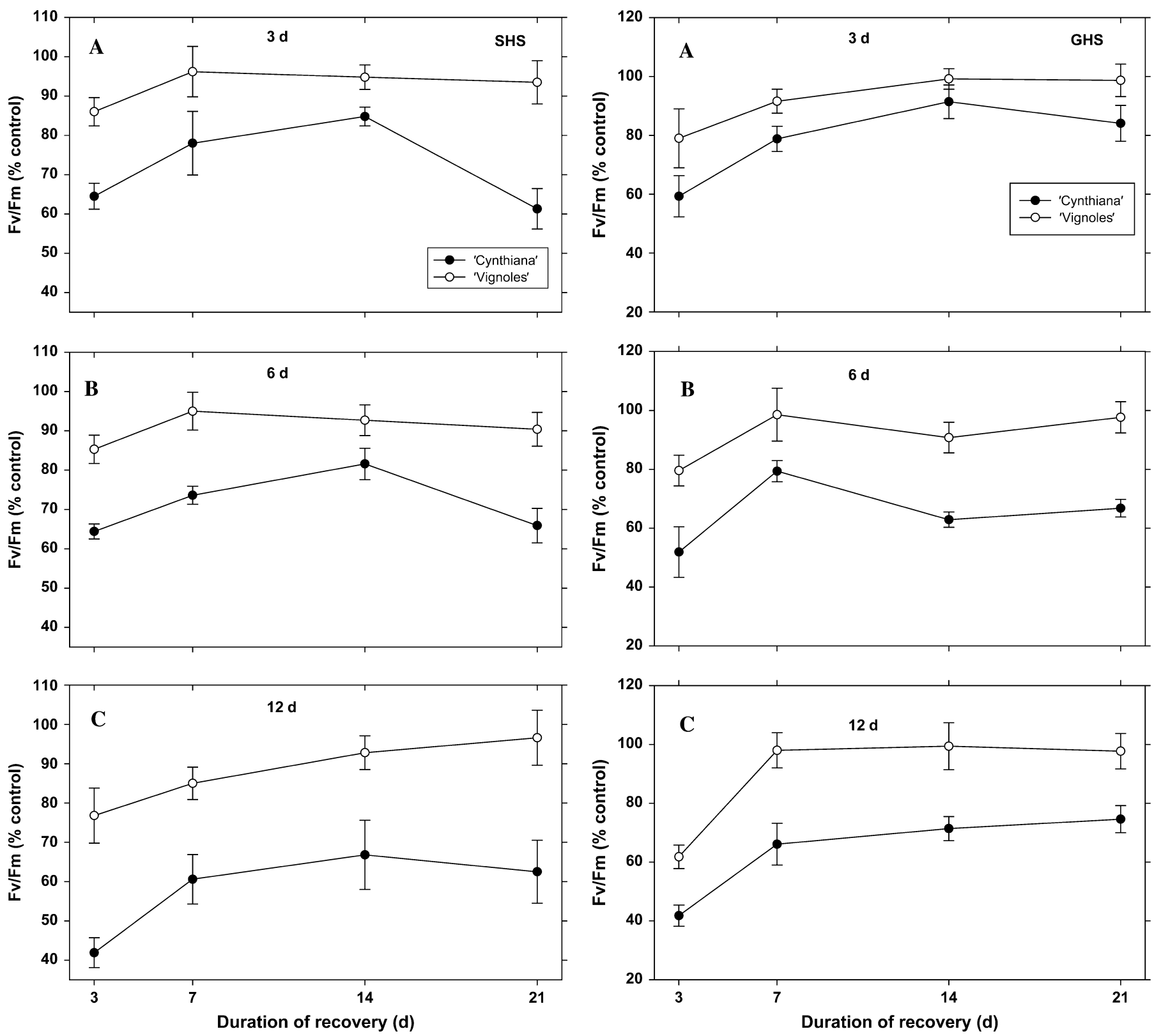

Fig. 2. Recovery of photosystem II expressed by the ratio of variable fluorescence and the maximum fluorescence $(\mathrm{Fv} / \mathrm{Fm})$ of 'Cynthiana' $(\bullet)$ and 'Vignoles' $(\bigcirc)$ of the most recent, fully expanded grape leaf under heat stress conditions. Four-month-old vines were exposed to sudden heat shock (SHS) for $3(\mathbf{A}), 6(\mathbf{B})$, and $12 \mathrm{~d}(\mathbf{C})$ at $40 / 35^{\circ} \mathrm{C}$ day/night (D/N) temperatures, $16 / 8$-h photoperiods, $550 \mu \mathrm{mol} \cdot \mathrm{m}^{-2} \cdot \mathrm{s}^{-1}$. photosynthetic photon flux $(P P F)$, and relative humidity $(\mathrm{RH})$ ranged between $40 \% \pm 10 \%$ during the light period to $70 \% \pm 10 \%$ during the night period. Chlorophyll fluorescence was measured after $3,7,14$, and $21 \mathrm{~d}$ of recovery from heat treatments in a greenhouse at $22 / 17 \pm 3{ }^{\circ} \mathrm{C} \mathrm{D} / \mathrm{N}$ temperatures, $50 \% \pm 10 \% \mathrm{RH}$, and $16 / 8-\mathrm{h}$ photoperiods. Supplemental light intensity on a horizontal plane above the canopy was $200 \mu \mathrm{mol} \cdot \mathrm{m}^{-2} \cdot \mathrm{s}^{-1} P P F$. The $\mathrm{Fv} / \mathrm{Fm}$ ratios of heat-stressed plants are expressed as a percentage of the control (measurements before applying heat treatments). A decrease in $\mathrm{Fv} / \mathrm{Fm}$ ratio indicates damage to thylakoid membranes; the lower the damage, the higher the tolerance to heat stress. A similar influence of heat treatments on $\mathrm{Fv} / \mathrm{Fm}$ was observed in a duplicate experiment. Vertical lines through data points are SE. The control values for $\mathrm{Fv} / \mathrm{Fm}$ at SHS measured under greenhouse conditions were 0.59 for 'Cynthiana' and 0.69 for 'Vignoles', respectively.

Fig. 3. Recovery of photosystem II system expressed by the ratio of variable fluorescence and the maximum fluorescence $(\mathrm{Fv} / \mathrm{Fm})$ of 'Cynthiana' $(\bullet)$ and 'Vignoles' $(O)$ of the most recent, fully expanded grape leaf under heat stress conditions. Four-month-old vines were exposed to gradual heat shock (GHS) for 3 (A), 6 (B), and $12 \mathrm{~d}(\mathbf{C})$ at $40 / 35^{\circ} \mathrm{C}$ day/night (D/N) temperatures, 16/8-h photoperiods, $550 \mu \mathrm{mol} \cdot \mathrm{m}^{-2} \cdot \mathrm{s}^{-1} P P F$, and relative humidity $(\mathrm{RH})$ ranged between $40 \% \pm 10 \%$ during the light period to $70 \% \pm 10 \%$ during the night period. Chlorophyll fluorescence was measured after 3, 7, 14, and $21 \mathrm{~d}$ of recovery from heat treatments in a greenhouse at $22 / 17 \pm 3{ }^{\circ} \mathrm{C} \mathrm{D} / \mathrm{N}$ temperatures, $50 \% \pm 10 \% \mathrm{RH}$, and 16/8-h photoperiods. Supplemental light intensity on a horizontal plane above the canopy was $200 \mu \mathrm{mol} \cdot \mathrm{m}^{-2} \cdot \mathrm{s}^{-1} P P F$. The $\mathrm{Fv} / \mathrm{Fm}$ ratios of heat-stressed plants are expressed as a percentage of the control (measurements before applying heat treatments). A decrease in $\mathrm{Fv} / \mathrm{Fm}$ ratio indicates damage to thylakoid membranes; the lower the damage, the higher the tolerance to heat stress. A similar influence of heat treatments on $\mathrm{Fv} / \mathrm{Fm}$ was observed in a duplicate experiment. Vertical lines through data points are SE. The control values for $\mathrm{Fv} / \mathrm{Fm}$ at SHS and GHS measured under greenhouse conditions were 0.63 for 'Cynthiana' and 0.71 for 'Vignoles', respectively. 
'Cynthiana' exposed to GHS might not be enough to improve thermal stability of the photosynthetic apparatus compared with 'Vignoles'.

Total leaf area of 'Cynthiana' and 'Vignoles' under both heat treatments was reduced (Table 1). Nonetheless, GHS heat treatment was less detrimental than SHS. Progressive decline in LA of 'Cynthiana' was observed after 3, 6, and $12 \mathrm{~d}$ of exposure to SHS, whereas decline in LA of 'Vignoles' was observed after $12 \mathrm{~d}$ of exposure to SHS. There was no significant difference in LA of 'Cynthiana' exposed to GHS during the first $6 \mathrm{~d}$ of treatment. After $12 \mathrm{~d}$ of heat treatment, LA was significantly reduced to $40 \%$ of the control. The LA of 'Vignoles' exposed to $12 \mathrm{~d}$ of GHS treatment was not significantly reduced. In general, 'Vignoles' had greater LA than that of 'Cynthiana' plants under both heat treatments.

Leaf, shoot, and root biomass of 'Cynthiana' and 'Vignoles' subjected to both heat treatments for 3, 6, and $12 \mathrm{~d}$ were determined after $21 \mathrm{~d}$ of recovery under greenhouse conditions (Table 2). Leaf and shoot biomass for 'Cynthiana' and 'Vignoles' vines under SHS and GHS heat treatments followed the same LA pattern. An earlier study indicated that shoot growth was reduced by more than $50 \%$ in 'Cynthiana' vines exposed to heat stress for 4 weeks (Kadir, 2005). Reduction in leaf and shoot biomasses may be attributed to reduction of photosynthesis and increase in leaf senescence as the result of damage to photosynthetic apparatus (Costa et al., 2002; Kim and Portis, 2005; Ladjal et al., 2000; Liu et al., 2006) or lack of movement of photosynthetic assimilates among different sinks (Naor et al., 2002).

In general, root biomass of 'Cynthiana' and 'Vignoles' was unaffected by heat stress treatments, except 'Cynthiana' roots were significantly reduced after $12 \mathrm{~d}$ of exposure to SHS treatment compared with that of $6 \mathrm{~d}$ of exposure. A difference in root biomass between the two cultivars under GHS stress was insignificant. The degree of susceptibility of shoot and root systems to heat stress in this study agrees with the work of Kadir (2005) in which shoots of 'Cynthiana' plants exposed to $40{ }^{\circ} \mathrm{C}$ for $28 \mathrm{~d}$ were more sensitive to high temperature than the roots. It should be noted that the root system in this study might have been subjected to temperatures higher that field-grown plants under relatively similar conditions.

Negative relationship between Fv/Fm and SHS and GHS treatments was observed (data not shown), whereas a positive relationship between Fv/Fm and LA was observed for both

Table 1. The effect of sudden heat shock (SHS) and gradual heat shock (GHS) treatments for 3, 6, and $12 \mathrm{~d}$ on total leaf area (LA) of Cynthiana and Vignoles grapes after $21 \mathrm{~d}$ of recovery from heat treatments under greenhouse conditions. ${ }^{\mathrm{z}}$

\begin{tabular}{|c|c|c|c|c|}
\hline \multirow[b]{3}{*}{ Duration of heat stress (d) } & \multicolumn{4}{|c|}{ LA $(\% \text { control })^{\mathrm{yx}}$} \\
\hline & \multicolumn{2}{|c|}{ SHS } & \multicolumn{2}{|c|}{ GHS } \\
\hline & Cynthiana & $\overline{\text { Vignoles }}$ & Cynthiana & Vignoles \\
\hline 3 & $56 \mathrm{a}$ & $85 \mathrm{a}$ & $70 \mathrm{a}$ & $90 \mathrm{a}$ \\
\hline 12 & $19 \mathrm{c}$ & $35 \mathrm{~b}$ & $40 \mathrm{~b}$ & $71 \mathrm{a}$ \\
\hline
\end{tabular}

ㄱlants were exposed to heat treatments for 3,6 , and $12 \mathrm{~d}$ at 40 day $/ 35 \mathrm{night}{ }^{\circ} \mathrm{C}(\mathrm{D} / \mathrm{N}), 16 / 8$-h photoperiods, $550 \mu \mathrm{mol} \cdot \mathrm{m}^{-2} \cdot \mathrm{s}^{-1} P P F$, and relative humidity $(\mathrm{RH})$ ranged between $40 \% \pm 10 \%$ during the light period to $70 \% \pm 10 \%$ during the night period. LA of the control and treated plants was measured after $21 \mathrm{~d}$ of recovery from heat treatments under greenhouse conditions of $22 / 17 \pm 3{ }^{\circ} \mathrm{C} \mathrm{D} / \mathrm{N}$ temperatures, $50 \% \pm 10 \% \mathrm{RH}$, and $16 / 8-\mathrm{h}$ photoperiods. Supplemental light intensity on a horizontal plane above the canopy was $200 \mu \mathrm{mol} \cdot \mathrm{m}^{-2} \cdot \mathrm{s}^{-1} P P F$.

${ }^{y}$ Data are expressed as a percentage of the control plant under greenhouse conditions. Means within column with different letters are significantly different using Fisher's least significant difference test. Each value is a mean of nine vines.

${ }^{x}$ Control values for SHS and GHS were: 1027 and $1018 \mathrm{~cm}^{2}$ for Cynthiana and 1018 and $1020 \mathrm{~cm}^{2}$ for Vignoles, respectively.

Table 2. The effects of sudden heat shock (SHS) and gradual heat shock (GHS) treatments for 3, 6, and 12 d on leaf dry weight (LDW), shoot dry weight (SDW), and root dry weight (RDW) of Cynthiana and Vignoles grapes after $21 \mathrm{~d}$ of recovery from heat treatments under greenhouse conditions. ${ }^{\mathrm{z}}$

\begin{tabular}{|c|c|c|c|c|c|c|}
\hline \multirow[b]{3}{*}{ Duration of heat stress (d) } & \multicolumn{6}{|c|}{ SHS } \\
\hline & \multicolumn{2}{|c|}{ LDW (\% control $)^{\mathrm{yx}}$} & \multicolumn{2}{|c|}{ SDW (\% control) } & \multicolumn{2}{|c|}{ RDW (\% control) } \\
\hline & Cynthiana & $\overline{\text { Vignoles }}$ & Cynthiana & $\overline{\text { Vignoles }}$ & Cynthiana & $\overline{\text { Vignoles }}$ \\
\hline 3 & $50 \mathrm{a}$ & $71 \mathrm{a}$ & $48 \mathrm{a}$ & $68 \mathrm{a}$ & $60 \mathrm{ab}$ & $59 \mathrm{a}$ \\
\hline 12 & $17 \mathrm{c}$ & $48 \mathrm{~b}$ & $20 \mathrm{c}$ & $54 \mathrm{~b}$ & $52 \mathrm{~b}$ & $50 \mathrm{a}$ \\
\hline & \multicolumn{6}{|c|}{ GHS } \\
\hline 3 & $77 \mathrm{a}$ & $93 \mathrm{a}$ & $75 \mathrm{a}$ & $90 \mathrm{a}$ & $84 \mathrm{a}$ & $92 \mathrm{a}$ \\
\hline 12 & $54 \mathrm{~b}$ & $79 \mathrm{a}$ & $53 \mathrm{~b}$ & $70 \mathrm{a}$ & $64 \mathrm{a}$ & $77 \mathrm{a}$ \\
\hline
\end{tabular}

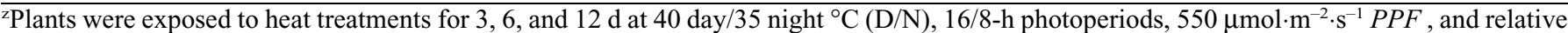
humidity $(\mathrm{RH})$ ranged between $40 \% \pm 10 \%$ during the light period to $70 \% \pm 10 \%$ during the night period. Dry tissue biomass of the control and treated plants was measured after $21 \mathrm{~d}$ of recovery from heat treatments under greenhouse conditions of $22 / 17 \pm 3{ }^{\circ} \mathrm{C} \mathrm{D} / \mathrm{N}$ temperatures, $50 \% \pm$ $10 \% \mathrm{RH}$, and 16/8-h photoperiods. Supplemental light intensity on a horizontal plane above the canopy was $200 \mu \mathrm{mol} \cdot \mathrm{m}^{-2} \cdot \mathrm{s}^{-1} P P F$.

${ }^{y}$ Data are expressed as a percentage of the control plant under greenhouse conditions. Means within column with different letters are significantly different using Fisher's least significant difference test. Each value is a mean of nine vines.

${ }^{\mathrm{x}}$ Control values for LDW at SHS and GHS were: 5.79 and $5.3 \mathrm{~g}$ for Cynthiana and 8.6 and $8.1 \mathrm{~g}$ for Vignoles, respectively. Control values for SDW at SHS and GHS were 2.57 and $2.9 \mathrm{~g}$ for Cynthiana and 7.88 and $8.2 \mathrm{~g}$ for Vignoles, respectively. Control values for RDW at SHS and GHS were 15.4 and $14.9 \mathrm{~g}$ for Cynthiana and 33.1 and $32.2 \mathrm{~g}$ for Vignoles, respectively. 
cultivars, although cultivars differed in their response to the heat treatments. Both cultivars responded similarly to GHS treatment with $\mathrm{R}^{2}=0.98$ for 'Cynthiana' and $\mathrm{R}^{2}=0.95$ for 'Vignoles'. Nonetheless, a higher relationship was observed under SHS treatment for 'Vignoles' $\left(\mathrm{R}^{2}=0.98\right)$, compared with 'Cynthiana' $\left(\mathrm{R}^{2}=0.80\right)$. This might indicate that decline in LA in 'Vignoles' is closely associated with the reduction in $\mathrm{FV} / \mathrm{Fm}$ or PSII damage. The observed correlation between $\mathrm{Fv} / \mathrm{Fm}$ and LA in 'Cynthiana' suggests that other photosynthetic processes might be involved. Although damage to PSII contributes to the inhibition of photosynthesis under heat stress, decrease in the Rubisco (ribulose-1,5-bisphosphate carboxylase/oxygenase) activation state occurs at temperatures lower than those required to reduce $\mathrm{Fv} / \mathrm{Fm}$ or damage PSII apparatus (Haldimann and Feller, 2005). Therefore, inactivation of Rubisco might be another factor that contributed to the inhibition of photosynthesis in 'Cynthiana'.

Results in this study show that 'Cynthiana' and 'Vignoles' have different photosynthetic capacities and ability to recover from heat stress conditions. The photosynthetic apparatus of 'Cynthiana' was significantly damaged under heat stress treatments and did not fully recover. This indicates that the photochemical reaction of 'Vignoles' was more thermostable and has greater ability to recover from SHS and GHS heat stress of $40^{\circ} \mathrm{C}$ compared with 'Cynthiana'. The gradual exposure to high temperature was more effective in improving photochemical efficiency of PSII in 'Vignoles' than in 'Cynthiana'. Therefore, 'Vignoles' might be more heat-resistant to high temperature than 'Cynthiana'. A decline in the efficiency of PSII under GHS heat treatment occurred in the growth chambers, although field plants might be better able to tolerate high temperatures. Progressive acclimation to elevated temperatures in the field involves coordinated changes in several photosynthetic apparatuses and processes that might help plants to survive heat stress. These results suggest that heat tolerance of grapevines grown in warm regions could be improved by selecting cultivars with high photochemical activity as manifested by high maximum quantum efficiency of PSII and capacity to recover after heat stress.

\section{Literature Cited}

Bukhov, N.G., C. Wiese, S. Neimanis, and U. Herber. 1999. Heat sensitivity of chloroplasts and leaves: Leakage of protons from thylakoids and reversible activation of cyclic electron transport. Photosyn. Res. 59:81-93.

Costa, E.S., R. Bressan-Smith, J.G. Oliveira, E. Campostrini, and C. Pimentel. 2002. Photochemical efficiency in bean plants (Phaseolus vulgaris L. and Vigna unguiculata L. Walp) during recovery from high temperature stress. Brazilian J. Plant Physiol. 14:105-110.

Crafts-Brandner, S.J. and M.E. Salvucci. 2002. Sensitivity of photosynthesis in a C4 plant, maize, to heat stress. Plant Physiol. 129:1773-1780.

Enami, I., M. Kitamura, T. Tato, Y. Isokawa, H. Ohta, and S. Kato. 1994. Is the primary cause of thermal inactivation in spinach PS II membranes release of the $33 \mathrm{kDa}$ protein or of Mn? Biochim. Biophys. Acta Bioenergetics. 1186:52-58.

Gulen, H. and A. Eris. 2003. Some physiological changes in strawberry (Fragaria $\times$ ananassa 'Camarosa') plants under heat stress. J. Hort. Sci. Biotechnol. 78:894-898.

Haldimann, P. and U. Feller. 2005. Growth at moderately elevated temperature alters the physiological response of photosynthetic apparatus to heat stress in pea (Pisum sativum L.) leaves. Plant Cell Environ. 28:302-317.
Havaux, M. 1993. Characterisation of thermal damage to the photosynthetic electron transport system in potato leaves. Plant Sci. 94:19-33.

Kadir, S. 2005. Growth of Vitis vinifera L. and Vitis aestivalis Michx. as affected by temperature. Intl. J. Fruit Sci. 5:67-80.

Kadir, S. 2006. Thermostability of photosynthesis of Vitis aestivalis Michx. and Vitis vinifera L. J. Amer. Soc. Hort. Sci. 131:476-483.

Kim, K. and A.R. Portis, Jr. 2005. Temperature dependence of photosynthesis in Arabidopsis plants with modifications in rubisco activase and membrane fluidity. Plant Cell Physiol. 46:522-530.

Kouřil, R., D. Lazár, P. Skotnica, P. Krchňak, and J. Nauš. 2004. High temperature induced chlorophyll fluorescence rise in plants at 40-50 ${ }^{\circ} \mathrm{C}$ : Experimental and theoretical approach. Photosyn. Res. 81:49-66. Ladjal, M., D. Epron, and M. Ducrey. 2000. Effect of drought preconditioning on thermotolerance of photosystem II and susceptibility of photosynthesis to heat stress in cedar seedlings. Tree Physiol. 20:1235-1241.

Law, R.D. and S.J. Crafts-Brandner. 1999. Inhibition and acclimation of photosynthesis to heat stress is closely correlated with activation of ribulose-1,5-bisphosphate carboxylase/oxygenase. Plant Physiol. 120:173-181.

Liu, Y., Q.Q. Huang, B.Y. Ma, and L.G. Xu. 2006. Changes of photosynthesis and physiological index in Vetiveria zizanioides under heat and drought stress. For. Res. 19:638-642.

Méthy, M., D. Gillon, and C. Houssard. 1997. Temperature-induced changes of photosystem II activity in Quercus ilex and Pinus halepensis. Can. J. For. Res. 27:31-38.

Moffatt, J.M., R.G. Sears, and G.M. Paulsen. 1990. Wheat high temperature tolerance during reproductive growth. II. Evaluation by chlorophyll fluorescence. Crop Sci. 30:881-885.

Naor, A., Y. Gal, and B. Bravdo. 2002. Shoot and cluster thinning influence vegetative growth, fruit yield, and wine quality of 'Sauvignon blanc' grapevines. J. Amer. Soc. Hort. Sci. 127:628-634.

Olson, B.L.S., K. Al-Khatib, P. Stahlman, and P.J. Isakson. 2000. Efficacy and metabolism of MON 37500 in Tititicum aestivum and weedy grass species as affected by temperature and soil moisture. Weed Sci. 48:541-548.

Paulsen, G.M. 1994. High temperature responses of crop plants, p. 365-389. In: K.J. Boot, J.M. Bennett, T.R. Sinclair, and G.M. Paulsen (eds.). Physiology and determination of crop yield. ASA, CSSA, SSSA Inc., Madison, WI.

Ramsey, F.L. and D.W. Schafer. 1997. The statistical sleuth: a course in methods of data analysis. Duxbury Press, Belmont, CA.

Schreiber, U. and W. Bilger. 1987. Rapid assessment of stress effects on plant leaves by chlorophyll fluorescence measurements, p. 27-53. In: J.D. Tenhunen, F.M. Catarino, O.L. Lange, and W.C. Oechel (eds.). Plant response to stress. Springer-Verlag, Berlin-Heidelberg, Germany.

Sepúlveda, G. and W.M. Kliewer. 1986. Stomatal response of three grape cultivars ( $V$. vinifera L.) to high temperature. Amer. J. Enol. Viticult. 37:44-52.

Sinsawat, V., J. Leipner, P. Stamp, and Y. Frachebound. 2004. Effect of heat stress on the photosynthetic apparatus in maize (Zea mays L.) growth at control or high temperature. Environ. Exp. Bot. 52:123-129.

Srivastava, A., B. Guissé, H. Greppin, and R.J. Strasser. 1997. Regulation of antenna structure and electron transport in photosystem II of Pisum sativum under elevated temperature probed by the fast polyphasic chlorophyll $a$ fluorescence transient: OKJIP. Biochim. Biophys. Acta Bioenergetics 1320:95-106.

Weis, E. and J. Berry. 1988. Plant and high temperature stress. Symp. Soc. Exp. Biol. 42:329-346.

Wen, X., H. Gong, and C. Lu. 2005. Heat stress induces a reversible inhibition of electron transport at the acceptor side of photosystem II in a cyanobacterium Spirulina platensis. Plant Sci. 168:1471-1476.

Wise, R.R., A.J. Olson, S.M. Schrader, and T.D. Sharkey. 2004. Electron transport is the functional limitation of photosynthesis in field-grown pima cotton plants at high temperature. Plant Cell Environ. 27:717-724. 